\title{
Natural Preservatives from Fruit Peels
}

\section{Tanuja Ashok Patil ${ }^{1}$ and Lolly Jain ${ }^{2 *}$}

${ }^{1}$ Microbiology Department, K.J. Somaiya College of Science and Commerce, Mumbai, India

${ }^{2}$ Associate Professor, Microbiology Department, K.J. Somaiya College of Science and Commerce, Mumbai, India

*Corresponding Author: Lolly Jain, Associate Professor, Microbiology Department, K. J. Somaiya College of Science and Commerce, Mumbai, India.
Received: April 18, 2020

Published: May 28, 2020

(C) All rights are reserved by Tanuja Ashok

Patil and Lolly Jain.

\begin{abstract}
In all packaged foods and cosmetics preservatives play an important role. Synthetic preservatives have been reported to be unhealthy and can be carcinogenic too. Thus, natural antioxidants as preservatives are gaining attention because of their remarkable characteristics of prevention of auto-oxidation in fats, oils and fat containing products. Thus, this study is undertaken to extract antioxidants to be used as preservatives. It involves extraction of compounds from sunlight dried fruit peels of Papaya, Watermelon and Kiwi by two methods: cold percolation and Soxhlet extraction methods using ethanol as solvent. In addition to determining antimicrobial activity by agar cup method, qualitative analysis for phenolic content, antioxidant content determination by Folin-Ciocalteu method and reductive power assay methods were also performed. Application of all fruit peel extracts as natural preservative is an important aspect of this study. All three fruit peel extracts were added to freshly prepared face-Cream in different concentrations and further stored. Sensory analysis and efficacy testing of preservatives in face cream was also done to detect its effectivity. Amongst all, Papaya fruit peels showed high amount of antioxidants followed by Kiwi and Watermelon extracts. All extracts showed considerable amount of efficacy as preservative in face cream preparations.
\end{abstract}

Keywords: Fruit Peels Extracts; Antioxidant Activity; Reductive Power Assay; Phenolic Activity; Preservative

\section{Abbreviations}

K (C): Kiwi fruit peel extracts by cold percolation method; K(S): Kiwi fruit peel extracts by Soxhlet method; W(C): Watermelon fruit peel extracts by cold percolation method; $W(S)$ : Watermelon fruit peel extracts by Soxhlet method; P(C): Papaya fruit peel extracts by cold percolation method; $\mathrm{P}(\mathrm{S})$ : Papaya fruit peel extracts by Soxhlet method

\section{Introduction}

A preservative is defined as any compound or molecule which is capable of inhibiting, retarding or arresting the growth of microorganisms, or of marking the evidence of any such detoriation. Preservatives are of three types: Antioxidants, Antimicrobials, Anti-browning agents. Biologically relevant definition of antioxidants is "synthetic or natural substances added to products to prevent or delay their deterioration by action of oxygen in air or in surrounding environment. In biochemistry and medicine, antioxidants are enzymes or other organic substances, such as vitamin E or $\beta$-carotene, that are capable of counteracting the damaging effects of oxidation in animal tissues" [1]. Antioxidants decrease the oxidative damage mediated by free radicals [2]. The most commonly used antioxidants are ascorbic acid [E 300], sodium ascorbate [E 301], calcium ascorbate [E 302], fatty acid esters of ascorbic acid [E 304], tocopherols [E 306], $\alpha$-tocopherol [E 307], $\gamma$-tocopherol [E 308], $\delta$-tocopherol [E 309], tert-Butylhydroquinone [TBHQ E-319], Butylated hydroxyanisole [BHA E-320], Butylated hydroxytoluene [BHT] $[3,19]$. Foods are generally consumed for their nutritive value and bioactive compounds [4]. Fruit wastes and their byproducts are formed in great amounts during industrial processing and hence represent a waste management problem, as they exert impact on the environment. So, they need to be managed or can be utilized as it is or by converting into any form [5]. For another choice of preservatives, the use of natural materials with antimicrobial potential is possible. The fruit peels have antioxidant and antimicrobial potential and hence these active compounds extracted from peels can be an alternate for the chemical preservatives used 
traditionally. Papaya, botanical name Carica papaya, is a lozenge tropical fruit, often seen in orange-red, yellow-green and yelloworange hues, with a rich orange pulp. Along with delicious taste, whole plant parts, fruit, roots, bark, peel, seeds and pulp have medicinal properties. Many benefits of papaya are due to high content of Vitamins A, B and C and also proteolytic enzymes like papain and chymopapain which have antiviral, antifungal and antibacterial properties $[6,20]$. Watermelon produces a fruit that is about 93\% water, hence the name "water" melon. The "melon" part came from the fact that the fruit is large and round and has a sweet, pulpy flesh. [7]. The fruit is usually globose to oblong or ellipsoid, sometimes ovoid, 5 - $70 \mathrm{~cm}$ long and weighing $0.1-3.0 \mathrm{~kg}$ [0.1 - $2.5 \mathrm{~kg}$ in water contain melon, $1.5-3.0 \mathrm{~kg}$ in watermelon] [8]. Actinidia deliciosa is a sub-family of the genus Actinidia, which is also known as Chinese gooseberry, kiwifruit, etc. in China, and consists of 55 - 60 species. Kiwi fruit has been used as mild laxative and a rich source of vitamins. Actinidia deliciosa has thereby recently acquired interest due to its attractive potential application in indigenous drugs. Kiwi fruit are oval, about the size of a large hen's egg [5 - $8 \mathrm{~cm} / 2$ - 3 in long and $4.5-5.5 \mathrm{~cm} / 13 / 4$ - 2 in diameter] [9,22].

\section{Aim of the Study}

Aim of the study was to obtain extracts of sundried fruit peels of 3 different fruits by Soxhlet apparatus and cold percolation method using ethanol as solvent. Extracts studied for qualitative analysis for phenolic content, and antimicrobial activity by agar cup method. Followed by application of extracts as preservatives in face cream which is further tested for efficacy testing and sensory evolution.

\section{Materials and Methods}

\section{Preparation of dried form of fruit peel}

Fruit peels of the selected fruits were collected from fruit juice vendor. Samples were washed thrice with tap water and then thrice with distilled water. Water traces were removed using filter paper. Then peels were dried completely under shade for 5 - 6 Days. Dried peels were ground to powder using electric blender and kept in air tight container.

\section{Preparation of ethanolic extract of fruit peels}

Ethanolic extracts of sample were prepared by soaking of 20 gms of dried sample in $100 \mathrm{~mL}$ of $95 \%$ ethanol overight and filtered through whatman filter paper No.1. This extract obtained using cold percolation method was stored for further study at $2-8^{\circ} \mathrm{C}$. Grounded samples were further processed to obtain extract using Soxhlet apparatus at $65^{\circ} \mathrm{C}$ for $15 \mathrm{hrs}$. Concentrated extracts were obtained and employed for further study.
Determination of phenolic content and antioxidant activity of extracts

Phenolic content and antioxidant activity of extracts were determined qualitatively by Folin-Ciocaltea method and reducing power assay respectively. For phenolic activity and for antioxidant activity Gallic acid were used as Positive control.

\section{Determination of antimicrobial activity}

The 18 hours grown culture of Bacillus spp., Staphylococcus aureus ATCC 6538, C. diphtheriae ATCC 13812, Escherichia coli ATCC 25922. Proteus spp., Pseudomonas aeruginosa ATCC 27853, Candida albicans ATCC 10231, Aspergillus niger spp. were suspended in Sterile saline and the optical density was adjusted to 0.1 O.D. at $620 \mathrm{~nm}$. Then, $1 \mathrm{~mL}$ of test culture was added to molten Nutrient agar and Potato Dextrose agar for antimicrobial study of bacterial and yeast and mold cultures respectively. Well mixed culture and agar was then poured in petri plate. With the aid of a sterile Cork borer of 8 $\mathrm{mm}$ diameter, equidistant wells were made in the seeded agar and the wells labeled accordingly. Using a micro pipette approximately $50 \mu \mathrm{L}$ of the reconstituted extracts at the various dilutions were placed into each well to fill up. Solvent i.e. 95\% ethanol was used as control in one of the punched wells. The plates were allowed to stand for an hour to allow for proper diffusion of extracts into the solidified medium after which they were incubated in an upright position for 24- 48 hours at the optimum temperature of growth . After incubation, zones of inhibition were measured to nearest millimeter [mm]. The set of test were performed in triplicate [24].

\section{Application of extracts as preservatives in face cream}

Stearic acid, lanolin, mineral oil and $0.1 \%$ of Potassium Sorbate are exposed to heat slowly on medium flame till they melt. Molten mixture is slowly poured into sterile distilled water and stirred continuously. Semisolid obtained is allowd to come at room temerature and then transfered into a container. Similarly, in another preparation $0.1 \%$ fruit peel extracts were added in perparation of face cream instead of Potassium sorbate. Efficacy testing of Presevatives in Face cream is as per standard process given for efficacy testing of preservative in cosmetics by CTFA method $[10,18]$.

\section{Results and Discussion}

The present study was conducted with an aim of determining antioxidant and antimicrobial properties of ethanolic extracts of dried fruit peels of papaya, watermelon and kiwi and study of its effect in face cream as preservative. Total phenolic content and antioxidant activity was determined by Follin-Ciocalteu's and reductive power assay respectively. Also, antimicrobial activity of ex- 
tracts was checked against 8 cultures. Application of preservative in face cream was compared with chemical preservative i.e. potassium sorbate. Similarly based on preliminary sensory study, $0.1 \%$ ethanolic extract was added in face cream. Standard protocol was followed for efficacy testing of preservative in cosmetic by CTFP method. On comparative scale, methanol and ethanol are best solvents for extraction [16]. The experimental results are presented and discussed in the following sections.

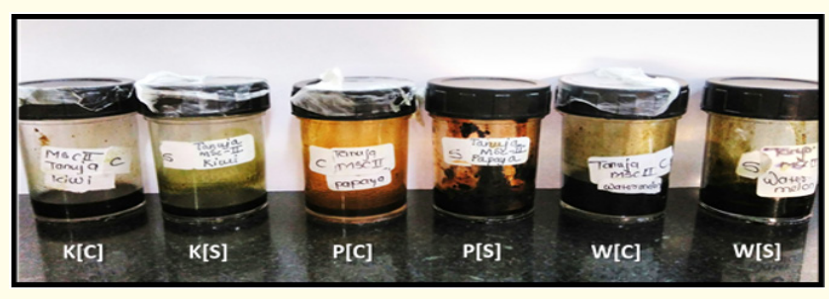

Figure 1: Extract of fruit peels by cold percolation and Soxhlet apparatus.

Phenolic content was found to be highest in kiwi extracts obtained by soxhlet method i.e. $16.00 \mathrm{mg} / \mathrm{g}$ and least in watermelon cold percolation extracts i.e. $6.90 \mathrm{mg} / \mathrm{g}$. Literature indicated phenol content with variation in concentration. Polyphenolic compounds are commonly found in both edible and inedible plants [11]. Watermelon peel water extracts shows $18.47 \pm 0.94 \mathrm{mg} \mathrm{GAE} / 100 \mathrm{~g}$ of total phenol content [12]. A study reported that juice of watermelon shows lowest amount of phenolic activity than other compared juice $[13,14]$ relating with present study. Also, in the study Soxhlet extraction shows higher extraction efficiency than cold percolation. Antioxidant activity of any substance is correlated with phenolic content of substance. In this study qualitative antioxidant activity is determined by reducing power assay. Antioxidant activity is associated with reducing power activity. Compounds with reducing power indicate that they are electron donor and can reduce oxidized intermediates. Various shades of development of blue and green are obtained from test solution which depends on reducing power of each compound. In study, watermelon Soxhlet extracts showed high antioxidant activity and least in kiwi cold percolation extracts. In one study antioxidant activity was papaya > kiwi > watermelon $[15,21]$. Also, kiwi has highest antioxidant activity [8].

Antimicrobial activity of extracts mentioned in table 1 .

\begin{tabular}{|c|c|c|c|c|c|c|c|}
\hline \multirow{3}{*}{ Test organism } & \multicolumn{7}{|c|}{ Zone of inhibition in $\mathrm{mm}$} \\
\hline & \multicolumn{2}{|c|}{ Papaya Fruit Peels } & \multicolumn{2}{|c|}{ Watermelon Fruit Peels } & \multicolumn{2}{|c|}{ Kiwi Fruit Peels } & \multirow[b]{2}{*}{ Solvent } \\
\hline & $\begin{array}{c}\text { Soxhlet } \\
\text { Apparatus }\end{array}$ & $\begin{array}{c}\text { Cold } \\
\text { Percolation }\end{array}$ & $\begin{array}{c}\text { Soxhlet } \\
\text { Apparatus }\end{array}$ & $\begin{array}{c}\text { Cold } \\
\text { Percolation }\end{array}$ & $\begin{array}{c}\text { Soxhlet } \\
\text { Apparatus }\end{array}$ & $\begin{array}{c}\text { Cold } \\
\text { Percolation }\end{array}$ & \\
\hline Bacillus spp & 13 & 12 & 13 & 11 & 15 & 13 & 9.5 \\
\hline Staphylococcus aureus ATCC 6538 & $\mathrm{R}$ & $\mathrm{R}$ & 12 & $\mathrm{R}$ & $\mathrm{R}$ & $\mathrm{R}$ & $\mathrm{R}$ \\
\hline C. diphtheria ATCC 13812 & 12 & 14 & 13 & - & 13.5 & 12 & 11 \\
\hline Escherichia coli ATCC 25922 & 10 & 11 & 14 & 12 & 9.5 & 11 & 9.5 \\
\hline Proteus spp. & $\mathrm{R}$ & $\mathrm{R}$ & $\mathrm{R}$ & $\mathrm{R}$ & $\mathrm{R}$ & $\mathrm{R}$ & $\mathrm{R}$ \\
\hline Pseudomonas aeruginosa ATCC 27853 & $\mathrm{R}$ & $\mathrm{R}$ & $\mathrm{R}$ & $\mathrm{R}$ & 15 & 12 & $\mathrm{R}$ \\
\hline Candida albicans ATCC 10231 & $\mathrm{R}$ & 11 & 13 & 13 & 11 & 14 & 9 \\
\hline Aspergillus niger. spp & 11 & 10.5 & 12 & 11 & 10 & 12 & 9 \\
\hline
\end{tabular}

Table 1: Zone of inhibition for all fruit peel extracts in $\mathrm{mm}$.

Key: "R": Resistant.

The antibacterial property of all 3 fruit peels extracts is determined by Agar cup method. All extracts showed antibacterial activity against different cultures. Among all extracts, Soxhlet apparatus extracts showed higher antibacterial activity than extracts obtained by cold percolation method. Many studies have reported antibacterial activity of different parts of fruits. In one of the study, kiwi showed highest antifungal and anti-candidial activity whereas watermelon had considerable anti-candidial activity on comparative basis [17]. Also, only kiwi extracts inhibited Pseudomonas spp. growth and $S$. aureus was inhibited by watermelon extracts.
In this study, kiwi fruit peel extracts showed highest antibacterial activity against Bacillus spp. Similar to other studies watermelon extracts showed inhibition against $S$. aureus. From the three fruit peels extracts with use of ethanol, watermelon extracts showed higher antibacterial activity against $C$. diphtheriae followed by kiwi and Papaya fruit peels. Escherichia coli was inhibited by all extracts with variation in the extent of inhibition. Proteus was found to be resistant against all extracts whereas Candida albicans, Aspergillus niger were found to be inhibited in considerable value by all 3 extracts. 


\begin{tabular}{|c|c|c|c|c|c|c|c|c|c|c|c|c|c|c|c|}
\hline & \multicolumn{15}{|c|}{ Total viable Count after incubation } \\
\hline & \multicolumn{3}{|c|}{$\begin{array}{c}\text { Escherichia coli ATCC } \\
25922\end{array}$} & \multicolumn{3}{|c|}{$\begin{array}{c}\text { Staphylococcus aureus } \\
\text { ATCC } 6538\end{array}$} & \multicolumn{3}{|c|}{$\begin{array}{l}\text { Pseudomonas aerugi- } \\
\text { nosa ATCC } 27853\end{array}$} & \multicolumn{3}{|c|}{ Aspergillus niger } & \multicolumn{3}{|c|}{$\begin{array}{l}\text { Candida albicans } \\
\text { ATCC } 10231\end{array}$} \\
\hline & $1^{\text {st }}$ Day & $7^{\text {th }}$ Day & $14^{\text {th }}$ Day & $1^{\text {st }}$ Day & $7^{\text {th }}$ Day & $14^{\text {th }}$ Day & $1^{\text {st }}$ Day & $7^{\text {th }}$ Day & $14^{\text {th }}$ Day & $1^{\text {st }}$ Day & $7^{\text {th }}$ Day & $14^{\text {th }}$ Day & $1^{\text {st }}$ Day & $7^{\text {th }}$ Day & $14^{\text {th }}$ Day \\
\hline $\begin{array}{l}\text { Papaya fruit } \\
\text { peel e x } \\
\text { tracts }\end{array}$ & $\begin{array}{c}5.8 x \\
10^{7}\end{array}$ & $4 \times 10^{6}$ & $2.1 \times 10^{5}$ & $\begin{array}{c}2.9 x \\
10^{7}\end{array}$ & $\begin{array}{c}1.9 x \\
10^{6}\end{array}$ & $1.2 \times 10^{5}$ & $9 \times 10^{7}$ & $\begin{array}{c}1.2 \mathrm{x} \\
10^{6}\end{array}$ & $1 \times 10^{6}$ & $\begin{array}{c}3.5 x \\
10^{7}\end{array}$ & $1 \times 10^{6}$ & $61.9 \times 10^{5}$ & $\begin{array}{c}15 \mathrm{x} \\
10^{4}\end{array}$ & $8 \times 10^{3}$ & ${ }^{3} 1.2 \times 10^{1}$ \\
\hline $\begin{array}{l}\text { Watermelon } \\
\text { fruit peel e x } \\
\text { tracts }\end{array}$ & $\begin{array}{c}2.1 \mathrm{x} \\
10^{7}\end{array}$ & $\begin{array}{c}3.1 x \\
10^{6}\end{array}$ & $6 \times 10^{4}$ & $\begin{array}{c}1.2 \mathrm{x} \\
10^{7}\end{array}$ & $2 \times 10^{4}$ & $1.2 \times 10^{3}$ & $9 \times 10^{7}$ & $4 \times 10^{3}$ & $1.2 \times 10^{2}$ & $1 \times 10^{7}$ & $4 \times 10^{2}$ & $23.2 \times 10^{1}$ & $\begin{array}{c}1.2 \mathrm{x} \\
10^{7}\end{array}$ & $3 \times 10^{7}$ & $71.2 \times 10^{6}$ \\
\hline $\begin{array}{l}\text { Kiwi fruit } \\
\text { peel e x } \\
\text { tracts }\end{array}$ & $4 \times 10^{7}$ & $1 \times 10^{5}$ & $3.9 \times 10^{4}$ & $\begin{array}{c}2.8 x \\
10^{7}\end{array}$ & $8 \times 10^{5}$ & $1.7 \times 10^{4}$ & $5 \times 10^{7}$ & $\begin{array}{c}1.2 \mathrm{x} \\
10^{4}\end{array}$ & $1.2 \times 10^{3}$ & $5 \times 10^{6}$ & $5 \times 10^{4}$ & ${ }^{4} 3.1 \times 10^{2}$ & $1 \times 10^{6}$ & $8 \times 10^{3}$ & ${ }^{3} 1.4 \times 10^{1}$ \\
\hline Control & $\begin{array}{l}6.5 x \\
10^{7}\end{array}$ & $\begin{array}{c}2.5 \mathrm{x} \\
10^{7}\end{array}$ & $1.9 \times 10^{7}$ & $\begin{array}{c}7.3 \mathrm{x} \\
10^{7}\end{array}$ & $\begin{array}{c}2.4 \mathrm{x} \\
10^{7}\end{array}$ & $1.6 \times 10^{7}$ & $\begin{array}{c}2.6 \mathrm{x} \\
10^{7}\end{array}$ & $2 \times 10^{7}$ & $1.6 \times 10^{7}$ & $\begin{array}{c}2.3 x \\
10^{7}\end{array}$ & $\begin{array}{c}1.9 \mathrm{x} \\
10^{7}\end{array}$ & $1.2 \times 10^{7}$ & $\begin{array}{c}2.9 x \\
10^{7}\end{array}$ & $\begin{array}{c}2.6 \mathrm{x} \\
10^{7}\end{array}$ & $1.4 \times 10^{7}$ \\
\hline
\end{tabular}

Table 2: Efficacy testing of preservatives.

Effectiveness Test [AET] is a product quality test which is designed to be, so far as is possible, a reproducible biological measurement of the activity of the preservative system in a product. This test is required for multi-dose presentations of pharmaceuticals as well as anhydrous ointments that contain a preservative system. The Antimicrobial Effectiveness Test [AET] is a suspension test for microbial kill. In this design a controlled inoculum of the challenge organism[s] is added in suspension with the sample to be tested, and then the number of viable organisms determined at different time points. According to CTFA method, an effectively preserved system will reduce the viable bacterial level to less than $0.1 \%$ of the initial concentration by the $14^{\text {th }}$ day. For yeasts and molds, the viable level must decrease or remain the same. The concentration for all microorganisms must remain at or below these designated levels for the remainder of the test incubation period.

One of the challenge test revealed the commercial products as having low capacity for suppressing bacterial proliferation such as may be encountered during use. Commercial cosmetic creams did not possibly possess adequate preservative capacity to be able to bring about acceptable low levels of microbial contamination [18]. Also, in another study, it was observed that pathogen and potential pathogen microorganisms can be found in unused cosmetic products and also preservatives may be ineffective in preventing them [10]. On the basis of viable count of test and control sample at different time point, it is observed that all extracts showed considerable decrease in microbial load till $14^{\text {th }}$ day of analysis. Watermelon fruit peel extracts was effectively able to decrease viable count of all spiked organisms except Candida spp. comparing with control test sample. Kiwi fruit peel extracts decreases load of Pseudomonas spp and Candida spp by almost 4 log count. Efficacy test is in good agreement with antimicrobial study. As implicated in table 2 , extracts does not completely justifies requirement of preservatives action. Thus, application of extracts in higher concentration may give desirable and required results by standard protocol.

\section{Conclusion}

Nowadays, preservatives play important role in all form of processed and packed material. According to literature, chemical preservative which are mostly synthetic antioxidants impose side effect on body. The hazardous effects of synthetic antioxidants and the emergence of antibiotic resistant strains have revived the search for antioxidant and antimicrobial agents from natural sources. From different studies conducted on peels, it has been found that peels of fruits and vegetables hold a tremendous potential to serve as a source of newer, effective, safer and better antioxidant and antimicrobial agents. Thus, natural antioxidants are in focus so as to improve food quality. In this study, natural preservatives i.e. natural antioxidants were extracted from three fruit peels i.e. Papaya, watermelon and kiwi by Soxhlet apparatus and cold percolation process using absolute ethanol as solvent. This study revealed that all fruit peels had phenolic content, antioxidant and antibacterial activity in different concentration. This also suggests promising use of extracts in cosmetic industry. Thus, along with natural source of antioxidants; recycling of fruit waste is another innovative approach. This will help in waste management too. Application of these extracts also shows considerable effect as preservatives in face cream. This study also, contributes to the increasing database for the medicinal plant or could be used as antioxidant in food and medicinal preparations. Further development will lead to pure and more active preservatives which can be used in different products. 


\section{Significance Statement}

This study discovered that potential extracts having antioxidant activity, antibacterial activity that may be of use for the development of new preservatives in food and cosmetic industries.

\section{Bibliography}

1. Shofian Norshahida Mohamad., et al. "Effect of freeze-drying on the antioxidant compounds and antioxidant activity of selected tropical fruit". International Journal of Molecular Sciences 12.7 (2011): 4678-4692.

2. El-Aal Hala A Abd and Fathi T Halaweish. "Food Preservative Activity of Phenolic Compounds in Orange Peel Extracts (Citrus sinensis L.)" (2010).

3. Franco Rafael., et al. "Antioxidants versus Food Antioxidant Additives and Food Preservatives". Antioxidants 8.11 (2019): 542.

4. Banerjee A., et al. "In vitro study on antioxidant activity of Syzygium cumini fruit". Food Chemistry 90.4 (2005): 727-733.

5. Duda-Chodak A., et al. "Antioxidant properties of different fruit seeds and peels Acta scientiarum polonorum". Technologia Alimentaria 6.3 (2007):29-36.

6. Aravind G., et al. "Traditional and Medicinal Uses of Carica papaya". Journal of Medicinal Plants Studies 1.1 (2013): 07-15.

7. Oseni OA., et al. "Antioxidative and antidiabetic activities of watermelon (Citrullus lanatus) juice on oxidative stress in alloxan-induced diabetic male Wistar albino rats". Nigerian medical journal: journal of the Nigeria Medical Association 56.4 (2015): 272-277.

8. Carlsen Monica H., et al. "The total antioxidant content of more than 3100 foods, beverages, spices, herbs and supplements used worldwide". Nutrition Journal 9.3 (2010).

9. Patra Jayanta Kumar and Kwang-Hyun Baek. "Novel green synthesis of gold nanoparticles using Citrullus lanatus rind and investigation of proteasome inhibitory activity, antibacterial, and antioxidant potential". International Journal of Nanomedicine 10 (2015): 7253-7264.

10. Tan ASB., et al "Investigation of preservative efficacy and microbiological content of some cosmetics found on the market". Pakistan Journal of Pharmaceutical Sciences 26 (2013): 153157.
11. Marja P Kähkönen., et al." Antioxidant activity of plant extracts containing phenolic compounds". Journal of Agricultural and Food Chemistry 47.10 (1999): 3954-3962.

12. Singh., et al. "Phenolic Content and Antioxidant Capacity of Selected Cucurbit Fruits Extracted with Different Solvents". Journal of Nutrition and Food Sciences 6.6 (2016).

13. Al-Musharfi N., et al. "Comparison of Ascorbic Acid, Total Phenolic Content and Antioxidant Activities of Fresh Juices of Six Fruits Grown in Oman". Journal of Food Processing and Technology 6.11 (2015): 1-3

14. Deng, Gui-Fang., et al. "Potential of fruit wastes as natural resources of bioactive compounds". International Journal of Molecular Sciences 13.7 (2012): 8308-8323.

15. Chitturi S., et al. "Studies on protein content, protease activity, antioxidants potential, melanin composition, glucosinolate and pectin constitution with brief statistical analysis in some medicinally significant fruit peels". Der Pharmacia Lettre 5.1 (2013): 13-23.

16. Soma Singh., et al. "Extraction of Antioxidants from Fruit Peels and its Utilization in Paneer". Journal of Food Processing and Technology 5.7 (2014).

17. Nessma Ahmed El Zawawy. "Antioxidant, Antitumor, Antimicrobial Studies and Quantitative Phytochemical Estimation of Ethanolic Extracts of Selected Fruit Peels". International Journal of Current Microbiology and Applied Sciences 4.5 (2015): 298-309.

18. Sanchita Choubey., et al. "Methods for Evaluation of Microbiological Safety, Guidelines Governing the Quality and Survey On Microbial Contamination Of Commercial Cosmetic Products - A Review". World Journal of Pharmaceutical and Medical Research 3.8 (2017): 85-94.

19. Andrés Moure., et al. "Natural antioxidants from residual sources". Food Chemistry 72 (2001): 145-171.

20. Maisarah AM., et al. "Antioxidant analysis of different parts of Carica papaya". International Food Research Journal 20.3 (2013): 1043-1048.

21. Aysun Ozkan., et al. "Antioxidant capacity of juice from different papaya [Carica papaya L.] cultivars grown under greenhouse conditions in Turkey". Turkish Journal of Biology 35 2009 (2011): 619-625. 
22. Keyur V Shastri., et al. "Actinidia Deliciosa: A Review". International Journal of Pharmaceutical Sciences and Research (2015): 3543-3549.

23. Scott V W Sutton., et al. "Development of the Antimicrobial Effectiveness Test as USP Chapter". PDA Journal of Pharmaceutical Science and Technology 56.6 (2002): 300-311.

24. S Brandt Rose., et al. "Studies with the Agar Cup-Plate Method I. A Standardized Agar Cup-Plate Technique". Journal of Bacteriology 38.5 (1939): 525-537.

\section{Assets from publication with us}

- Prompt Acknowledgement after receiving the article

- Thorough Double blinded peer review

- Rapid Publication

- Issue of Publication Certificate

- High visibility of your Published work

Website: https://www.actascientific.com/

Submit Article: https://www.actascientific.com/submission.php Email us: editor@actascientific.com

Contact us: +919182824667 